\title{
Changes in T-Tubules and Sarcoplasmic Reticulum in Ventricular Myocytes in Early Cardiac Hypertrophy in a Pressure Overload Rat Model
}

\author{
Perla Pérez-Treviño Jorge Pérez-Treviño ${ }^{a}$ Cuauhtémoc Borja-Villa Noemí Garcíaa,b \\ Julio Altamirano ${ }^{\mathrm{a}, \mathrm{b}}$ \\ aEndowed Chair in Cardiology and Vascular Medicine, School of Medicine, Tecnológico de Monterrey, \\ Campus Monterrey, Monterrey, Mexico, 'Basic and Translational Research Center, Hospital Zambrano \\ Hellion, TEC Salud, San Pedro Garza-García, Mexico
}

\section{Key Words}

Cardiac hypertrophy • Calcium signaling - Pressure overload • Fluorescence recovery after photobleach • Sarcoplasmic reticulum • Transverse tubules

\begin{abstract}
Background/Aims: Pressure-overload (PO) causes cardiac hypertrophy $(\mathrm{CH})$, and eventually leads to heart failure (HF). HF ventricular myocytes present transverse-tubules (TT) loss or disarrangement and decreased sarcoplasmic reticulum (SR) density, and both contribute to altered $\mathrm{Ca}^{2+}$ signaling and heart dysfunction. It has been shown that TT remodeling precedes $\mathrm{HF}$, however, it is unknown whether SR structural and functional remodeling also starts early in CH. Methods: Using confocal microscopy, we assessed TT (with Di-8-ANNEPS) and SR (with SR-trapped Mag-Fluo-4) densities, as well as SR fluorophore diffusion (fluorescence recovery after photobleach; FRAP), cytosolic $\mathrm{Ca}^{2+}$ signaling and ex vivo cardiac performance in a PO rat hypertrophy model induced by abdominal aortic constriction (at 6 weeks). Results: Rats developed $\mathrm{CH}$, while cardiac performance, basal and upon $\beta$-adrenergic stimulation, remained unaltered. TT density decreased by $\sim 14 \%$, without spatial disarrangement, while SR density decreased by $\sim 7 \%$. More important, FRAP was $\sim 30 \%$ slower, but with similar maximum recovery, suggesting decreased SR interconnectivity. Systolic and diastolic $\mathrm{Ca}^{2+}$ signaling and SR Ca ${ }^{2+}$ content were unaltered. Conclusion: SR remodeling is an early $\mathrm{CH}$ event, similar to TT remodeling, appearing during compensated hypertrophy. Nevertheless, myocytes can withstand those moderate structural changes in SR and TT, preserving normal $\mathrm{Ca}^{2+}$ signaling and contractility.
\end{abstract}




\section{Cellular Physiology Cell Physiol Biochem 2015;37:1329-1344 \begin{tabular}{l|l} 
and Biochemistry Published online: October 22, 2015 & $\begin{array}{l}\text { Co 2015 S. Karger AG, Basel } \\
\text { www.karger.com/cpb }\end{array}$ \\
\hline
\end{tabular} \\ Pérez-Treviño et al.: T-Tubules and Sarcoplasmic Reticulum in Early Hypertrophy}

\section{Introduction}

Cardiac hypertrophy occurs in response to persistent physiological or pathological hemodynamic challenges, and heart and cell enlargement are accompanied by structural and functional remodeling at the whole heart, interstitial, subcellular and molecular level [1]. Pressure overload (PO) is one of the main stimuli that trigger the remodeling observed in pathological cardiac hypertrophy, which eventually progresses to heart failure (HF) [13]. It is well known that in hypertrophied cells from HF, the transverse tubules (TT), the highly specialized system of sarcolemmal invaginations in ventricular myocytes, undergoes remodeling, which includes disarrangement or disappearance of tubules [4-11]. Since TT contains most of the L-type $\mathrm{Ca}^{2+}$ channels, essential for the excitation-contraction coupling (ECC) [12], TT remodeling in HF affects ECC by delaying recruitment of clusters of $\mathrm{Ca}^{2+}$ release channels (RyR) of the sarcoplasmic reticulum (SR) by the sarcolemmal $\mathrm{Ca}^{2+}$ current, or failing to activate them $[4,5,8,13]$. Overt TT remodeling affects the spatial and temporal homogeneity of the systolic $\mathrm{Ca}^{2+}$ transient, which appears with blunted amplitude and slower time course, and all these impair the magnitude and rate of force development $[4,5$, $8,11]$. Nevertheless, TT remodeling is a progressive process and it has been suggested that it precedes HF $[11,14]$. Wei et al. showed that TT remodeling, in a PO model induced by thoracic aortic constriction (TAC), was apparent during compensated cardiac hypertrophy [14], while Shah et al. showed that increased TT alterations in uncompensated cardiac hypertrophy, assessed in the chronic spontaneously hypertensive rats (SHRs), correlated with worsening of cardiac function [11]. However, it is not known how early TT remodeling starts during PO-induced hypertrophy, and whether it is accompanied by remodeling of the closely associated SR.

The SR network is continuous and uniformly distributed throughout the cell volume $[15,16]$, and diffusion of lumenal $\mathrm{Ca}^{2+}$ allows homogenous diastolic $\mathrm{SR} \mathrm{Ca}^{2+}$ concentration at the whole cell level [17], as well as rapid local replenishment following spontaneous release, [17-19]. These ensure uniform $\mathrm{Ca}^{2+}$ release during ECC and avoids regional variations of RyR activity, due to varying lumenal $\mathrm{Ca}^{2+}$-dependent regulation [20], which could enhance spontaneous $\mathrm{Ca}^{2+}$ release $[21,22]$.

A number of studies have shown plasticity of the SR under normal and abnormal conditions. A recent report showed that the SR is a highly dynamic organelle, particularly during development, with continuous network branching and fusion, as well as intra network domain migration, and these dynamic processes also occurred in adult myocytes, albeit at lower frequency [23]. Recent reports; one in a sheep model of tachypacing-induced HF [16] and others in rat [9] and human HF [10], showed a 30\% decrease in SR density, accompanied by other ultra structural changes. Furthermore, SR plasticity has also been documented in transgenic animal models; calsequestrin (CSQ) knock out (CSQ-KO) increased SR volume [24], while mutated CSQ (R33Q knock-in) caused a 30\% decrease in junctional SR (jSR) [25]. Conditional SERCA-KO caused a $\sim 73 \%$ decrease in SR volume, while longitudinal TT largely increased, enhancing sarcolemmal $\mathrm{Ca}^{2+}$ entry [26]. Nevertheless, it has not been determined whether changes in SR density and SR interconnectivity occur during early stages of cardiac hypertrophy. Given the prominent role of the SR in intracellular $\mathrm{Ca}^{2+}$ cycling; removal, storage and release, structural changes in this organelle could potentially impact $\mathrm{Ca}^{2+}$ signaling and contractile performance. Here we assessed whether SR remodeling occurs in ventricular myocytes from a rat model of compensated cardiac hypertrophy induced by PO (at 6 weeks), and its possible repercussion in $\mathrm{Ca}^{2+}$ cycling. The relative SR density and network interconnectivity were assessed with confocal imaging of an SR-trapped fluorophore (Mag-Fluo-4) in permeabilized ventricular myocytes. SR interconnectivity was assessed by the extent and time course of lumenal Mag-Fluo-4 diffusion (fluorescence recovering after photobleach; FRAP). We found in hypertrophied myocytes (cellular volume increased by $\sim 78 \%$ ), a modest, but significant, $\sim 7 \%$ decrease in SR density. More important, there was a $\sim 30 \%$ decrease in the rate of intra SR fluorophore diffusion, suggesting a decrease in SR network interconnectivity or increased network "tortuosity". These changes coincided 


\section{Cellular Physiology Cell Physiol Biochem 2015;37:1329-1344

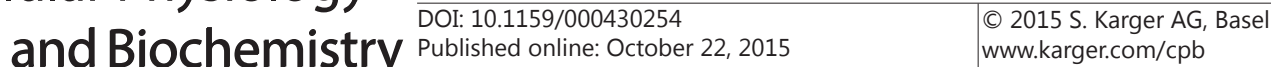 \\ Pérez-Treviño et al.: T-Tubules and Sarcoplasmic Reticulum in Early Hypertrophy}

with a $\sim 14 \%$ decrease in TT density (without altering its normal distribution pattern). Nevertheless, at this early stage of cardiac hypertrophy, both structural changes in SR and TT were not accompanied by alterations in intracellular $\mathrm{Ca}^{2+}$ signaling, since $\mathrm{Ca}^{2+}$ transients and spontaneous sparks, as well as the $\mathrm{SR} \mathrm{Ca}^{2+}$ content, were unchanged. Furthermore, ex vivo cardiac performance, at basal level and upon $\beta$-adrenergic stimulation, was unaltered. The data suggest that in rat hearts with compensated hypertrophy, moderate alterations in SR density and in its interconnectivity, accompanied by a modest decrease in TT, may appear as early as six weeks after AAC.

\section{Materials and Methods}

Reagents

Chemicals were obtained from Sigma-Aldrich, St. Louis, MO, USA, unless indicated otherwise. All fluorophores were obtained from Life Technologies, Carlsbad, CA, USA.

Rat model of pressure overload

These studies were approved by the Internal Committee for Care and Handling of Laboratory Animals of the School of Medicine of the Tecnológico de Monterrey (Protocol number 2012-012), and were performed following the NIH guidelines. We induced PO cardiac hypertrophy by abdominal aortic constriction (AAC) in male Wistar rats (250-350 g). Rats were anesthetized with pentobarbital sodium (30 mg/kg body weight, I.P.) and the surgical procedure was performed by laparotomy and exposure of the abdominal aorta proximal to the renal arteries, as described by others $[27,28]$. In the AAC group, the constriction was performed between the left renal artery and the superior mesenteric artery with prolene thread and a G-22 needle as a guide, which reduced the lumen of the aorta by 65\% [29], while age-paired sham-operated rats served as controls (Sham). Animals were fed with standard rat chow and provided water ad libitum. After 6 weeks of the surgical procedure, the animals were sacrificed and the ex vivo and in vitro studies were performed.

\section{Isolated heart mechanical performance}

Animals were anaesthetized with pentobarbital sodium ( $80 \mathrm{mg} / \mathrm{kg}$ body weight, I.P.), hearts were excised and mounted on a Langendorff apparatus, perfused retrogradely ( $12 \mathrm{ml} / \mathrm{min}$ ) with Krebs-Henseleit (K-H) buffer at $37^{\circ} \mathrm{C}$ and bubbled with $95 \% \mathrm{O}_{2} / 5 \% \mathrm{CO}_{2}$ gas. $\mathrm{K}-\mathrm{H}$ buffer had the following composition (in mM): $125 \mathrm{NaCl}, 5.4 \mathrm{KCl}, 1 \mathrm{MgCl}_{2}, 0.5 \mathrm{NaH}_{2} \mathrm{PO}_{4}, 25 \mathrm{NaHCO}_{3}, 2.5 \mathrm{CaCl}_{2}, 11$ glucose and 0.0001 octanoate [30]. A latex balloon connected to a pressure transducer was inserted into the left ventricle and filled with saline solution. Data were recorded with a Data-Trax acquisition system (World Precision Instruments, Sarasota, FL, USA). The hearts were perfused with K-H buffer and monitored for $30 \mathrm{~min}$. The myocardium performance index (MPI) was obtained from the analysis of $5 \mathrm{~min}$ of contraction data. MPI represents the product of Left Ventricular Developed Pressure $\times$ Heart rate (LVDP $\times$ HR; mm Hg $\times$ heart beats $\times$ $\mathrm{min}^{-1}$ ). Cardiac performance in response to stress was assessed by perfusing the hearts with K-H solution containing $100 \mathrm{nM}$ of the synthetic $\beta$-adrenergic agonist isoproterenol (ISO) during $10 \mathrm{~min}$.

\section{Acutely Isolated Ventricular Myocytes}

Myocytes isolation was performed following previously described procedures [31]. Briefly, hearts were excised from rats anaesthetized (as described above), and the heart was Langendorff-perfused with collagenase type II ( $1 \mathrm{mg} / \mathrm{ml}$; Worthington Biochemical Corporation, Lakewood, NJ, USA) at $37^{\circ} \mathrm{C}$. Afterwards, the ventricles were removed and cells were mechanically dissociated. Myocytes were stored in a normal Tyrode (NT) solution containing (in mM): $130 \mathrm{NaCl}, 5.4 \mathrm{KCl}, 0.5 \mathrm{MgCl}_{2}, 25 \mathrm{HEPES}, 22$ glucose, 0.33 $\mathrm{NaH}_{2} \mathrm{PO}_{4}$ and $1 \mathrm{CaCl}_{2}$ ( $\mathrm{pH} 7.4$ ), at room temperature. Experiments were performed in quiescent rod-shaped cells within 6 hours of isolation.

Cell volume and T-Tubules imaging

Acutely isolated rat myocytes were incubated at room temperature in NT containing calcein acetoxy methyl ester (AM; $5 \mu \mathrm{M})$ to assess cell volume or with Di-8-ANEPPS (10 $\mu \mathrm{M})$ to assess T-Tubules. After 20 


\section{Cellular Physiology Cell Physiol Biochem 2015;37:1329-1344 \begin{tabular}{ll|l} 
DOI: 10.1159/000430254 & $\begin{array}{l}\text { O 2015 S. Karger AG, Basel } \\
\text { www.karger.com/cpb }\end{array}$ \\
\hline
\end{tabular} \\ Pérez-Treviño et al.: T-Tubules and Sarcoplasmic Reticulum in Early Hypertrophy}

min of fluorophore incubation, the cells were washed with fluorophore-free NT and confocal imaging was performed after 30 min with a Leica TCS SP5 confocal microscope (Leica Microsystems, Wetzlar, Germany), equipped with a HCX PL APO 40×, 1.3 NA, oil immersion objective. Calcein or Di-8-ANEPPS were excited at $488 \mathrm{~nm}$ with an Argon laser. Emission was collected at 500-600 and $>600 \mathrm{~nm}$, for calcein and Di-8-ANEPPS, respectively. Confocal images of $512 \times 512$ pixels were acquired in the XY scan mode at $400 \mathrm{~Hz}$, with a pinhole optimized for a resolution of $0.4 \mu \mathrm{m}$ in the focal plane and $<1 \mu \mathrm{m}$ in the z-axis. Images were digitized at 8 bit resolution, with a pixel size of 210-360 $\mathrm{nm}$ for TT imaging and 230-430 for cell volume (depending on cell size).

For cell volume assessment, stacks of confocal sections separated by $1 \mu \mathrm{M}$ in the $\mathrm{z}$-axis covering the whole cell depth were acquired. Image processing and data analysis for cell volume was performed as described [32] using the public domain software "Image]" (http://rsb.info.nih.gov/ij/). Briefly, the cell area for each confocal plane was estimated by the pixel size multiplied by the number of pixels above a threshold, determined from the histogram of fluorescence intensity distribution. Cell volume was estimated by multiplying the area from each confocal section by the $\mathrm{z}$ step distance between confocal slices.

For the T-Tubule recording, we selected the center of the cell (in the z-axis), to avoid stained cell debris at the bottom of the chamber and the surface membrane, and acquired a stack of 10 confocal sections spaced every $100 \mathrm{~nm}$ along the z-axis. Each confocal section was the average of 4 frames from the same position, which allowed better structural resolution.

For the T-Tubule density analysis we used the full stack of 10 images, and it was performed as previously described [33,34]. Briefly, a region of interest (ROI) was outlined inside the whole cell. The ROI was drawn by hand and excluded the surface sarcolemma and nuclei. To estimate the area containing Di8-ANEPPS fluorescence, corresponding to the T-tubules, a threshold level was determined and data were analyzed as described above for cell volume. Results are presented as the relative "T-Tubule index" (TT index), which was obtained by dividing the total Di-8-ANEPPS fluorescence containing area by the total cell area from the 10 confocal slices, and normalized to Sham (\%). To assess the longitudinal spacing between TT (T-Tubule distribution) and overall organization, a Fast Fourier transform (FFT) was used to convert the two dimensional images from the spatial domain in the longitudinal axis into the frequency domain $[4,11$, 26]. For that purpose, the fluorescence profiles of two defined ROIs of $60 \times 0.5 \mu \mathrm{m}$ positioned in different locations along the longitudinal axis of the cell were processed to provide an estimate for each cell. Data are displayed as the power vs. distance.

Sarcoplasmic reticulum density assessed in saponin-permeabilized cells loaded with Mag-Fluo-4

Myocytes were incubated with the low affinity $\mathrm{Ca}^{2+}$ fluorescent probe Mag-Fluo- $4 \mathrm{AM}$ at $30^{\circ} \mathrm{C}$ during $30 \mathrm{~min}$, as described previously to favor fluorophore accumulation within the ER/SR lumen [35-38]. The fluorophore-loading solution contained (in $\mathrm{mM}$ ) $0.1 \mathrm{CaCl}_{2}, 0.0075$ Mag-Fluo-4 (AM), $130 \mathrm{NaCl}, 5.4 \mathrm{KCl}, 25$ HEPES, $1 \mathrm{MgCl}_{2}, 0.3 \mathrm{NaH}_{2} \mathrm{PO}_{4}$ and 20 glucose ( $\mathrm{pH}$ 7.4). Afterwards, cells were washed with a fluorophorefree solution, kept at room temperature and used within $1 \mathrm{~h}$.

To remove remaining cytosolic Mag-Fluo-4, myocytes were permeabilized with saponin as previously described [39]. Briefly, myocytes were incubated with a "relaxing" solution, containing (in mM) 100 K-aspartate, $20 \mathrm{KCl}, 3 \mathrm{MgATP}, 0.1 \mathrm{EGTA}, 0.0001 \mathrm{free}^{2+}{ }^{2+}, 1$ free $\mathrm{Mg}^{2+}$, $20 \mathrm{HEPES}, 3 \mathrm{~K}$-Glutamate and 3 Malic acid (pH 7.4). After $1 \mathrm{~min}$, the relaxing solution was replaced with a saponin-permeabilizing solution, containing (in $\mathrm{mM}$, unless otherwise indicated) $100 \mathrm{~K}$-aspartate, $20 \mathrm{KCl}, 3 \mathrm{MgATP}, 0.1 \mathrm{EGTA}, 0.0001$ free $\mathrm{Ca}^{2+}, 1$ free $\mathrm{Mg}^{2+}, 20$ HEPES, 3 K-glutamate, 3 Malic acid, 5 phosphocreatine di-Na, $5 \mathrm{U} / \mathrm{ml}$ creatine-phosphokinase, 2\% polyvinylpyrrolidone (PVP) and $0.007 \%$ saponin (pH 7.2). After 30-60 s, this solution was replaced by a saponin-free "internal" solution, containing (in mM, unless indicated): $100 \mathrm{~K}$-aspartate, $20 \mathrm{KCl}, 3 \mathrm{MgATP}$, 0.5 EGTA, 0.00002 free $\mathrm{Ca}^{2+}, 1$ free $\mathrm{Mg}^{2+}, 20$ HEPES, 3 K-glutamate, 3 Malic acid, 5 phosphocreatine di-Na, $5 \mathrm{U} / \mathrm{ml}$ Creatine-phosphokinase and 2\% PVP (pH 7.2). Experiments were performed within 15 min after permeabilization. $\mathrm{Ca}^{2+}$ and $\mathrm{Mg}^{2+}$ concentrations were calculated with the software Maxchelator [40].

Confocal images of $512 \times 512$ pixels were acquired in the XY scan mode, using the $488 \mathrm{~nm}$ Argon laser as the excitation wave length. Emission and other settings were as described above for cell volume. Stacks of three confocal sections separated by $100 \mathrm{~nm}$ in the center of the z-axis were acquired. For SR density assessment a region of interest (ROI) was outlined along the cell boundary. SR density analysis and data presentation were performed as described for T-tubules.

\section{KARGER}




\section{Cellular Physiology Cell Physiol Biochem 2015;37:1329-1344 \begin{tabular}{l|l} 
and Biochemistry $\begin{array}{l}\text { Published online: October 22, } 2015 \\
\text { Po 2015 S. Karger AG, Basel } \\
\text { www.karger.com/cpb }\end{array}$ \\
\hline
\end{tabular} \\ Pérez-Treviño et al.: T-Tubules and Sarcoplasmic Reticulum in Early Hypertrophy}

Fluorescence recovery after photobleach (FRAP) of sarcoplasmic reticulum-trapped Mag-Fluo-4

Myocytes were loaded with Mag-Fluo-4 and permeabilized with saponin as described above. X-Y images were acquired every $10 \mathrm{~s}$, and each image was acquired at $400 \mathrm{~Hz}$. After basal fluorescence was established (first 2 images), an ROI in the center of the cell (in the X-Y plane; ROI-a) of approximately $10 \times$ $10 \mu \mathrm{m}$ was photobleached using the $488 \mathrm{~nm}$ Argon laser line with $100 \%$ transmission (basal fluorescence and recovery images were acquired using $8 \%$ transmission for the excitation laser to minimize unintended Mag-Fluo-4 bleaching). The selected ROI-a was scanned 2 times, followed immediately by acquisition of a sequence of full X-Y images (each image was acquired every $10 \mathrm{~s}$ ) to establish the extent of photobleach and time course of recovery. Data acquisition lasted $300 \mathrm{~s}$. ImageJ was used to obtain the fluorescence profile of photobleached ROI-a and the parallel fluorescence decrease of a second ROI (ROI-b) situated $50 \mu \mathrm{m}$ away, in the longitudinal axis, from the bleached region. Mag-Fluo-4 FRAP time course data were represented as $\Delta \mathrm{F} /$ $\mathrm{F}_{0}(\%)$, where $\mathrm{F}$ is fluorescence at any given time and $\mathrm{F}_{0}$ is basal fluorescence before bleaching.

Confocal imaging of cytosolic $\mathrm{Ca}^{2+}$

Myocytes were incubated in NT solution containing Fluo-4 AM (10 $\mu \mathrm{M})$ during $30 \mathrm{~min}$, and washed afterwards with a fluorophore-free NT solution. Linescan images were recorded along the longitudinal axis of the cell, avoiding the nuclei, at $400 \mathrm{~Hz}$. Excitation, emission and other imaging parameters, were as described for cell volume and SR density recording. $\mathrm{Ca}^{2+}$ transients were evoked with a field-stimulator (MYP100 MyoPacer, IonOptix LLC, Milton, MA, USA). Diastolic $\mathrm{Ca}^{2+}$ sparks were acquired during 2-3 s after evoked $\mathrm{Ca}^{2+}$ transients returned to basal level.

The SR $\mathrm{Ca}^{2+}$ content was assessed by the amplitude of the cytosolic $\mathrm{Ca}^{2+}$ transient in response to rapid caffeine $(10 \mathrm{mM})$ application after a conditioning field stimulation train [41]. Fluo-4 fluorescence was presented as normalized $\mathrm{F} / \mathrm{F}_{0}$, as described above. $\mathrm{Ca}^{2+}$ sparks were characterized according to established criteria [42] using the ImageJ pluggin Sparkmaster [43].

\section{Statistics}

Data were presented as mean \pm standard error of the mean (SEM). $n$ represents the number of animals or cells studied. Unpaired Student's t-tests were performed and a P $<0.05$ was considered significant. Data processing and statistical analysis were performed with Microsoft Excel (2007, Redmond, WA, USA) and GraphPad Prism (V. 2.0, La Jolla, CA, USA). Graphs were prepared using Systat Sigma Plot (V. 12, San Jose, CA, USA).

\section{Results}

Whole heart and ventricular myocytes hypertrophy in AAC rats

At 6 weeks following AAC surgery, we found a significant $\sim 23 \%$ increase in the heart/femur weight ratio (from $0.92 \pm 0.05$ to $1.13 \pm 0.02 \mathrm{~g}^{\circ} \mathrm{g}^{-1}$, for Sham and AAC hearts, respectively, $\mathrm{P}<0.05$ ) (Fig. 1A). Cardiac hypertrophy was confirmed at the cellular level by assessing ventricular myocytes volume using confocal imaging. Figure $1 \mathrm{~B}$ shows representative images of Sham and AAC ventricular myocytes loaded with calcein. Pooled data showed (Fig. 1C) a 78\% volume increase in AAC ventricular myocytes (from $31.5 \pm 1.3$ pl to $56.0 \pm 4.4 \mathrm{pl}$, for Sham and AAC, respectively, $\mathrm{P}<0.05)$.

\section{Ex vivo cardiac contractility performance in AAC rats}

Cardiac contractility performance in AAC and Sham rats was assessed in isolated hearts under basal conditions. Pooled data of MPI assessed during $30 \mathrm{~min}$ for both heart types is shown in Fig. 2A. We found no difference in MPI in AAC hearts, compared to Sham (P>0.05). Furthermore, we assessed AAC and Sham MPI response to $\beta$-adrenergic stimulation. Fig. $2 \mathrm{~B}$ shows. Pooled data of the $\%$ increase in MPI at 10 min showed no significant difference in both heart types $(\mathrm{P}>0.05)$. These data suggest that at 6 weeks the AAC hearts were in compensated hypertrophy.

\section{KARGER}


Fig. 1. Cardiac hypertrophy assessed at the organ and cellular level in AAC rats. (A) Pooled data of the heart to femur weight ratio in Sham and AAC rats after 6 weeks of surgery ( $\mathrm{n}=5$ animals for each group). (B) Confocal sections from representative ventricular myocytes loaded with calcein. (C) Mean cell volume (pl) obtained from stacks of confocal sections acquired in the $\mathrm{z}$ axis $(\mathrm{n}=27$ cells/4 rats for Sham; 21 cells/4 rats for AAC). White bar in the AAC image represents $10 \mu \mathrm{m}$ and both cells share the same scale.

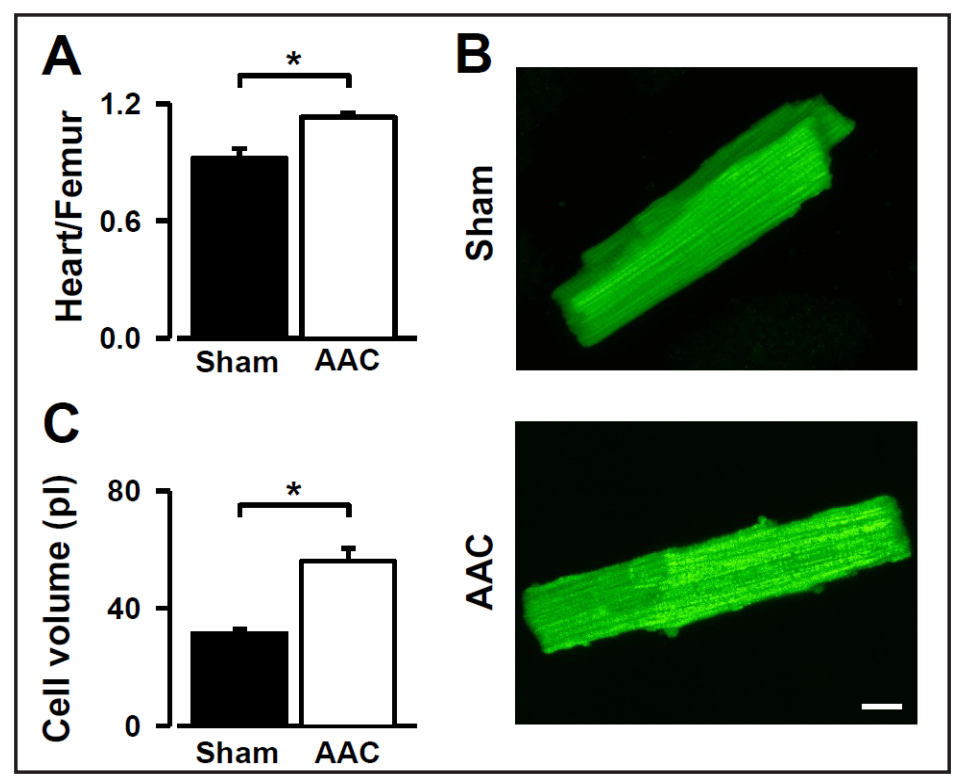

Fig. 2. Ex vivo mechanical performance in AAC hearts. (A) Basal mechanical performance index in AAC and Sham hearts ( $\mathrm{n}=3$ for Sham and AAC). MPI units are $\mathrm{mm}$ $\mathrm{Hg} \times$ heart beats $\times \mathrm{min}^{-1}$. (B) Normalized data of MPI of Sham and AAC hearts upon ISO exposure $(n=5$ for Sham and AAC).

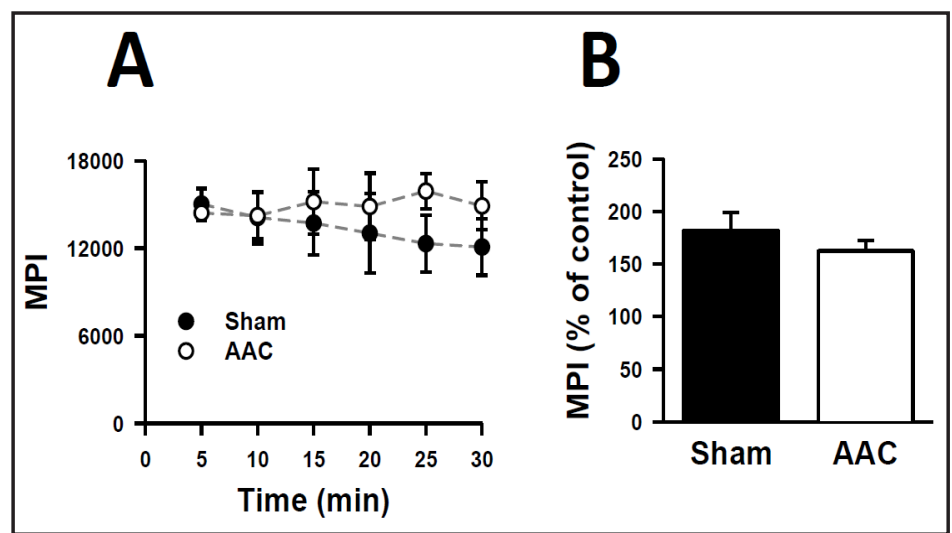

Structural changes in T tubules in AAC ventricular myocytes

It is well established that in HF the structural changes in TT contribute to altered $\mathrm{Ca}^{2+}$ signaling $[4,5,11]$ and heart performance $[11,14]$. We aimed to determine whether the AAC cells, in early stages of cardiac hypertrophy (at 6 weeks), presented TT alterations, as reported by Wei et al., after $\sim 9$ weeks in the more aggressive TAC rat model [14]. Figure 3A shows representative confocal images of both, Sham and AAC ventricular myocytes incubated with the lipophilic fluorophore Di-8-ANEPPS. In both cell types the TT system appears as highly organized transversal bands spaced periodically along the longitudinal axis of the cell. From z-stacks of 10 images per cell, as those shown in Fig. 3A, we assessed TT density (TT index) and TT longitudinal spacing, and we found a modest, but significant, decrease in AAC ventricular myocytes, compared with Sham ( 14\%; $\mathrm{P}<0.05$, Fig. 3B). The longitudinal TT distribution, assessed with a FFT, did not show differences in both cell types (Fig. 3C). The main peak of the power distribution was used to compute TT longitudinal periodicity, and corresponded to $1.81 \pm 0.01 \mu \mathrm{m}$ for Sham and $1.82 \pm 0.03 \mu \mathrm{m}$ for AAC (P>0.05), which are in agreement with the normal TT distribution found in previous studies $[4,6,14,44]$. Furthermore, there were no changes in the power of the main peak, which is an index of the regularity of longitudinal TT distribution $(2.24 \pm 0.01$ and $2.27 \pm 0.09$, for Sham and AAC, respectively, $\mathrm{P}>0.05$ ).

Structural changes in the sarcoplasmic reticulum in hypertrophied ventricular myocytes

Changes in SR structure and function in failing myocytes has been an intriguing issue, with important potential consequences for $\mathrm{Ca}^{2+}$ signaling, mechanical and electrical myocyte 
Fig. 3. T-tubule density and longitudinal distribution in AAC ventricular myocytes. (A) Representative confocal images from di-8-ANEPPS-stained Sham and AAC ventricular myocytes. Sections in the right represent a magnification of the regions within the rectangles in the main images. (B) Pooled data for the TT index in both cell types $(n=23$ cells/4 animals for Sham; 26 cells/4 animals for AAC). White bar in the AAC image represents $10 \mu \mathrm{m}$, and both cells share the same scale. (C) FFT power distribution (arbitrary units) along the longitudinal axis from di-8ANEPPS-stained Sham and AAC cells.

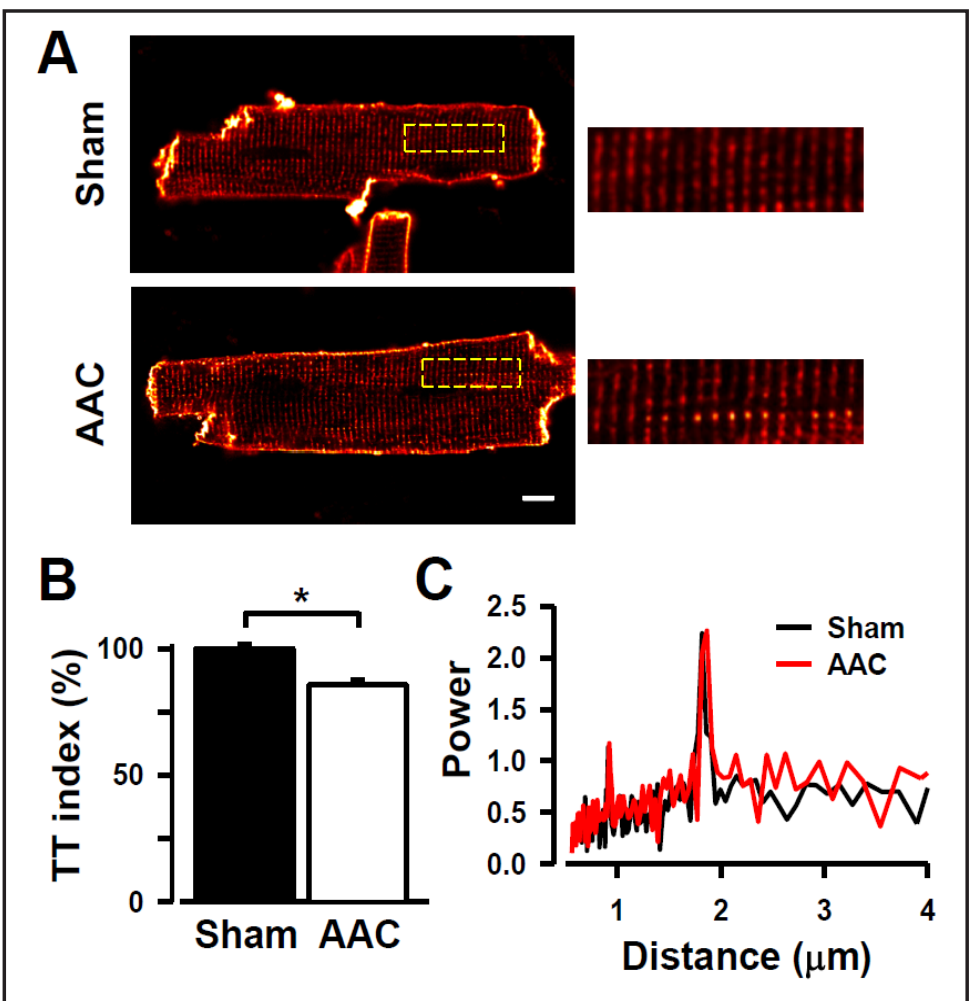

Fig. 4. Sarcoplasmic reticulum density in AAC ventricular myocytes. (A) Representative confocal images of intra-SR MagFluo-4 fluorescence in permeabilized Sham and AAC ventricular myocytes. Sections in the right represent a magnification of the regions within the rectangles in the main images. (B) Pooled data for the relative SR density (SR$\mathrm{D}(\%))$ in both cell types. $(\mathrm{n}=19$ cells/3 animals for Sham; 18 cells /4 animals for AAC). White bar in the AAC image represents $10 \mu \mathrm{m}$, and both cells share the same scale.

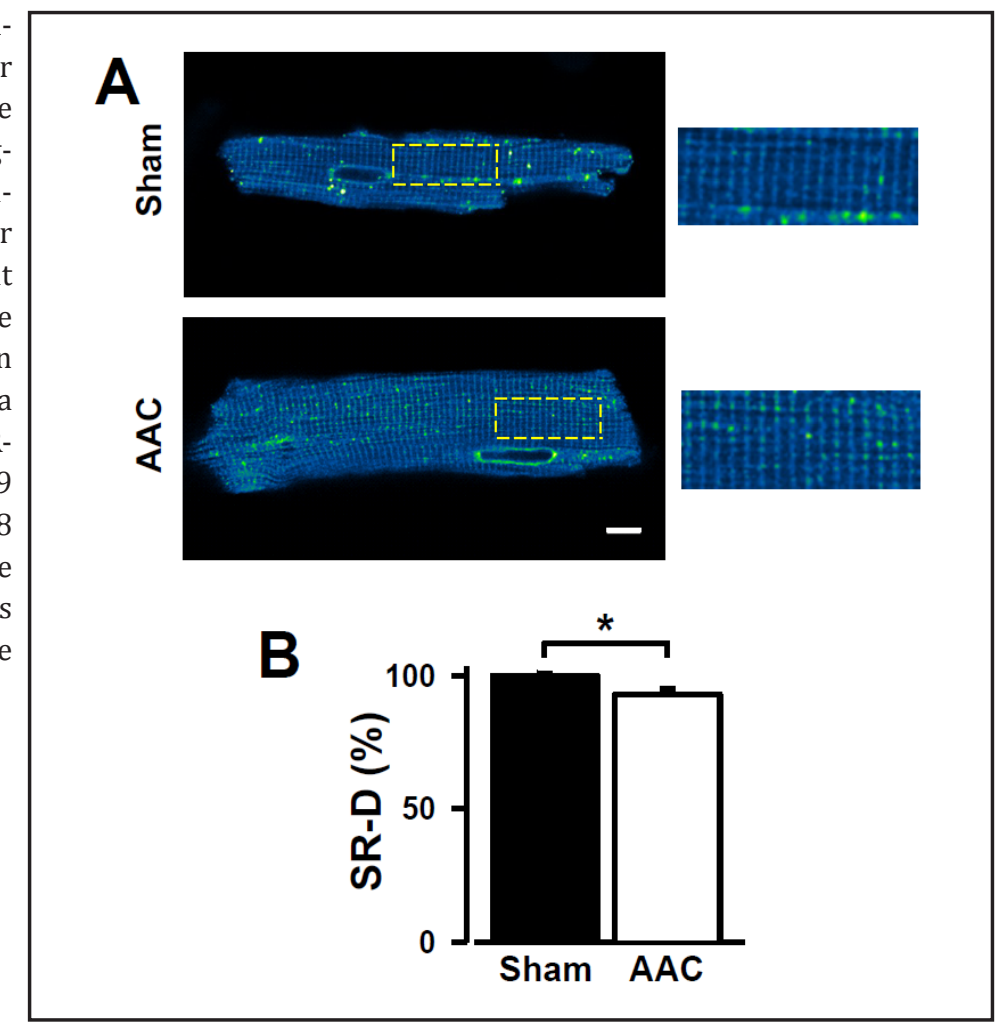

performance [17], as well as for protein processing and SR-mediated myocyte apoptosis $[45,46]$. Recent structural studies in myocytes from HF in human and animal models $[9,10$, 16] have shown decreased SR density, accompanied by other ultra structural dyad changes. However, it is unclear whether those structural changes appear late during HF progression or are events that could appear during early stages of cardiac hypertrophy. Furthermore,

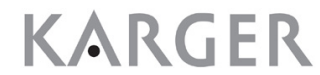


Fig. 5. Fluorescence recovery after photobleach of intra-SR Mag-Fluo-4 in AAC permeabilized ventricular myocytes. (A) Confocal images of FRAP of the intra-SR Mag-Fluo-4 at 0, 50, 100 and $150 \mathrm{~s}$ after photobleach in a Sham and an AAC cell. Letters a and $b$ within the upper images indicate the ROIs selected for assessing fluorescence recovery and decay, respectively. (B) Time course of FRAP for the Sham and AAC ventricular myocytes. (C) Time course of fluorescence decay of Mag-Fluo-4 at $50 \mu \mathrm{m}$ away from the bleached area.

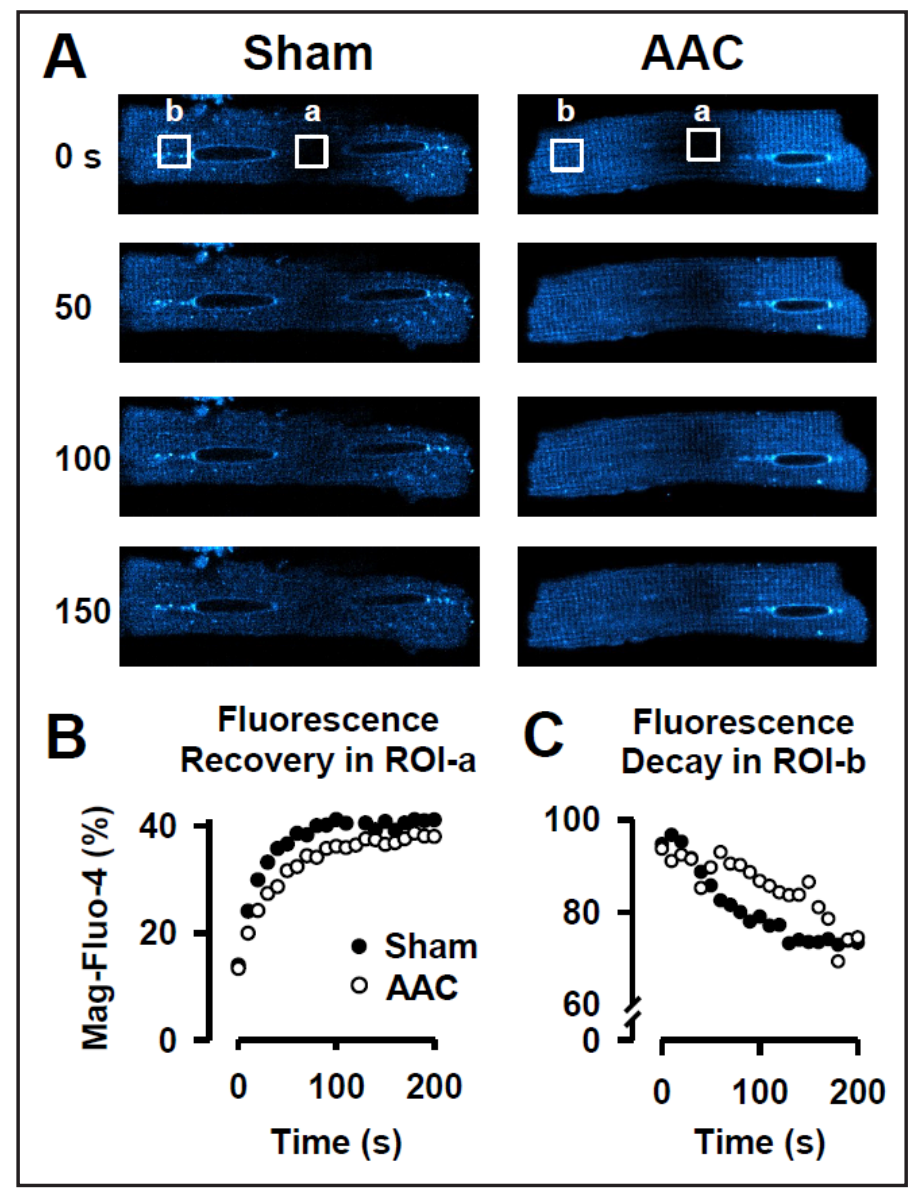

those previous studies did not provide data about the status of the network interconnectivity resulting from the structuralSR remodeling. Therefore, we assessed the relative SR density and the integrity of the SR network interconnectivity during compensated cardiac hypertrophy in AAC ventricular myocytes. For this purpose, we loaded the SR lumen with the low affinity $\mathrm{Ca}^{2+}$ indicator Mag-Fluo-4, followed by Saponin permeabilization of the sarcolemma. Figure $4 \mathrm{~A}$ shows representative confocal images of the SR for Sham and AAC cells. Pooled data (Fig. $4 \mathrm{~B})$ shows a small, but significant decrease $(\sim 7 \%)$ in relative SR density in AAC ventricular myocytes $(\mathrm{P}<0.05)$. SR network integrity was assessed with FRAP of Mag-Fluo-4 (Fig. 5). From those recordings, we evaluated both; Mag-Fluo-4 fluorescence recovery (in ROI-a), as well as fluorescence decrease in a distant region (in ROI-b; $50 \mu \mathrm{m}$ away in the longitudinal axis; Fig. 5A). Figure 5B and $C$ shows the time course of fluorescence change for ROI-a and ROI-b, respectively, for the Sham and the AAC ventricular myocytes shown in Fig. 5A. The time course of recovery in each cell type is apparently faster than that of decay. This is because the fluorescence recovery in the ROI-a depends on fluorophore diffusion from all adjacent regions; longitudinal as well as transversal. Single exponential fitting allowed determining the extent and time constant of fluorescence recovery $\left(\tau_{\text {recovery }}\right)$ in both cell types. Pooled data for this analysis is shown in Fig. 6 . We found a significant increase $(\sim 44 \%)$ in $\tau_{\text {recovery }}$ in AAC cells $(30.0 \pm 4.4$ and $43.2 \pm 4.8 \mathrm{~s}$, for Sham and AAC, respectively, $\mathrm{P}<0.05$; Fig. $6 \mathrm{~B})$. However, the maximum fluorescence recovery, assessed after $300 \mathrm{~s}$, was similar in both cell types ( $42.3 \pm 1.4$ and $40.7 \pm 1.2 \%$, for Sham and AAC, respectively, P>0.05; Fig. 6C). Pooled data for the time constant of decay ( $\tau_{\text {decay }}$ ) in the ROI-b (Fig. 6E) showed a $\sim 82 \%$ increase in AAC cells $(145.9 \pm 21.5$ and $265.6 \pm 46.6 \mathrm{~s}$, for Sham and AAC, respectively, $\mathrm{P}<0.05)$. Nevertheless, the maximum decay of Mag-Fluo-4 fluorescence after $300 \mathrm{~s}$ was similar in both cell types (67.6 \pm 2.6 and $71.8 \pm 2.8 \%$, for Sham and AAC, respectively, P>0.05; Fig. $6 \mathrm{~F}$ ). 
Fig. 6. Intra-SR Mag-Fluo-4 diffusion is slower in AAC ventricular myocytes. (A) Pooled data of the time course of intra-SR Mag-Fluo-4 fluorescence recovery in ROI-a. (B) Pooled data for the $\tau_{\text {recovery }}(\mathrm{n}=14$ cells $/ 4$ animals for Sham and AAC). (C) Maximum extent of fluorescence recovery at $300 \mathrm{~s}$ after bleach in the ROI-a. (D) Pooled data of the time course of Mag-Fluo-4 fluorescence decay in the ROI-b. (E) Pooled data for the $\tau_{\text {decay }}(n=12$ cells/4 animals for Sham; 11 cells $/ 4$ animals for AAC). (F) Maximum fluorescence decay in the ROI-b at $300 \mathrm{~s}$ after bleaching.

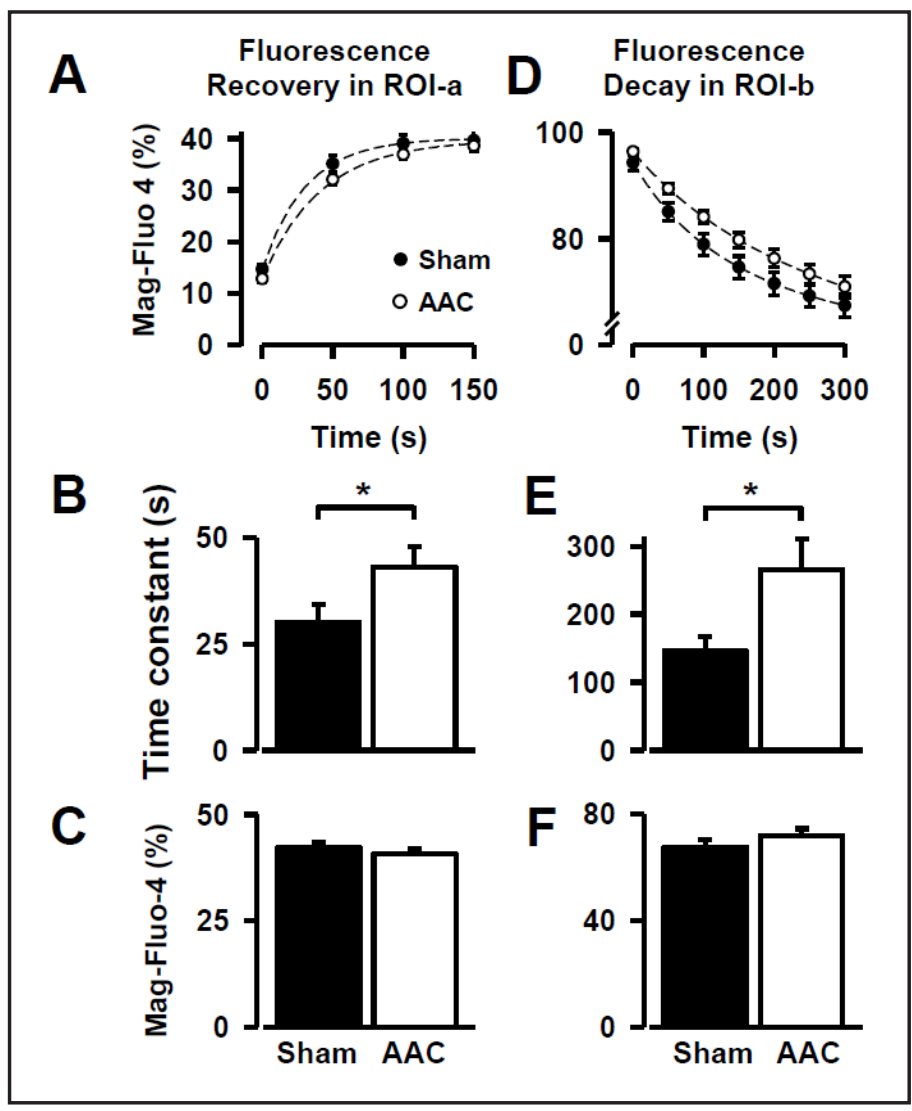

Fig. 7. Field-stimulated $\mathrm{Ca}^{2+}$ transients in AAC ventricular myocytes. (A) Representative confocal images for the time course of the cytosolic $\mathrm{Ca}^{2+}$ transients in Fluo-4-loaded sham and AAC ventricular myocytes. Traces below each image illustrate the time course of the normalized spatial average fluorescence. Vertical scale bar in the Sham image represents $20 \mu \mathrm{m}$, and both cells share the same scale. (B) Derivative of the time course of $\Delta \mathrm{F} / \mathrm{F}_{0}(\mathrm{dF} / \mathrm{dt} ; \% / \mathrm{ms})$ from the representative $\mathrm{Ca}^{2+}$ transients for Sham (black) and AAC (red). (C) Pooled data for $\mathrm{dF} / \mathrm{dt}$ from both cell types. (D) Pooled data for the normalized $\mathrm{Ca}^{2+}$ transient peak amplitude $(\Delta \mathrm{F} /$ $\mathrm{F}_{0}$ ) for Sham and AAC ventricular myocytes. (E) Time to $50 \%$ decay of the $\mathrm{Ca}^{2+}$ transient. ( $\mathrm{n}=50$ cells $/ 4$ animals for Sham; 47 cells/ 4 animals for $\mathrm{AAC}$ ).

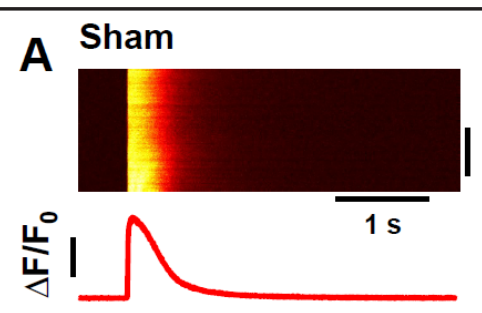

B
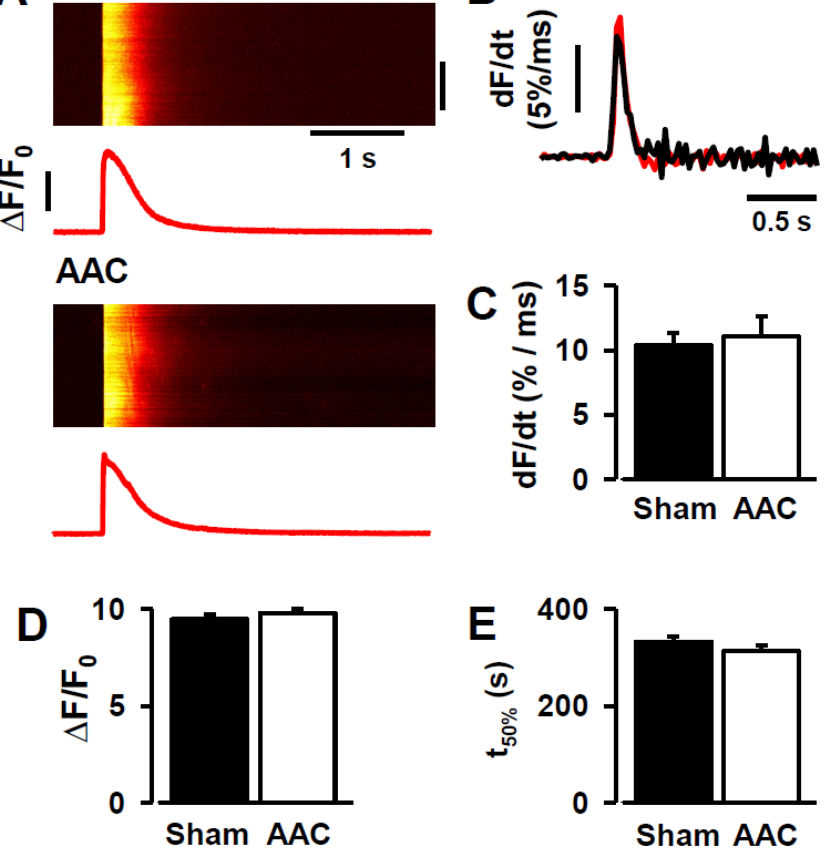

Cytosolic $\mathrm{Ca}^{2+}$ handling and $\mathrm{SR} \mathrm{Ca}^{2+}$ content in AAC ventricular myocytes

We assessed systolic and diastolic $\mathrm{Ca}^{2+}$ handling by recording field-stimulated $\mathrm{Ca}^{2+}$ transients and spontaneous $\mathrm{Ca}^{2+}$ sparks in Sham and AAC ventricular myocytes loaded 
Fig. 8. Spontaneous $\mathrm{Ca}^{2+}$ sparks in AAC ventricular myocytes. (A) Representative $\mathrm{Ca}^{2+}$ Sparks images from Sham and AAC ventricular myocytes loaded with Fluo4. (B) Pooled data for $\mathrm{Ca}^{2+}$ sparks frequency. (C) Spark Amplitude $\left(\Delta \mathrm{F} / \mathrm{F}_{0}\right)$. (D) $\mathrm{Ca}^{2+}$ spark duration, assessed as the time above the $50 \%$ level of the peak (full-duration-half-maximum; FDHM). Sham $=82$ cells $/ 4$ animals, $\mathrm{AAC}=69$ cells $/ 4$ animals.

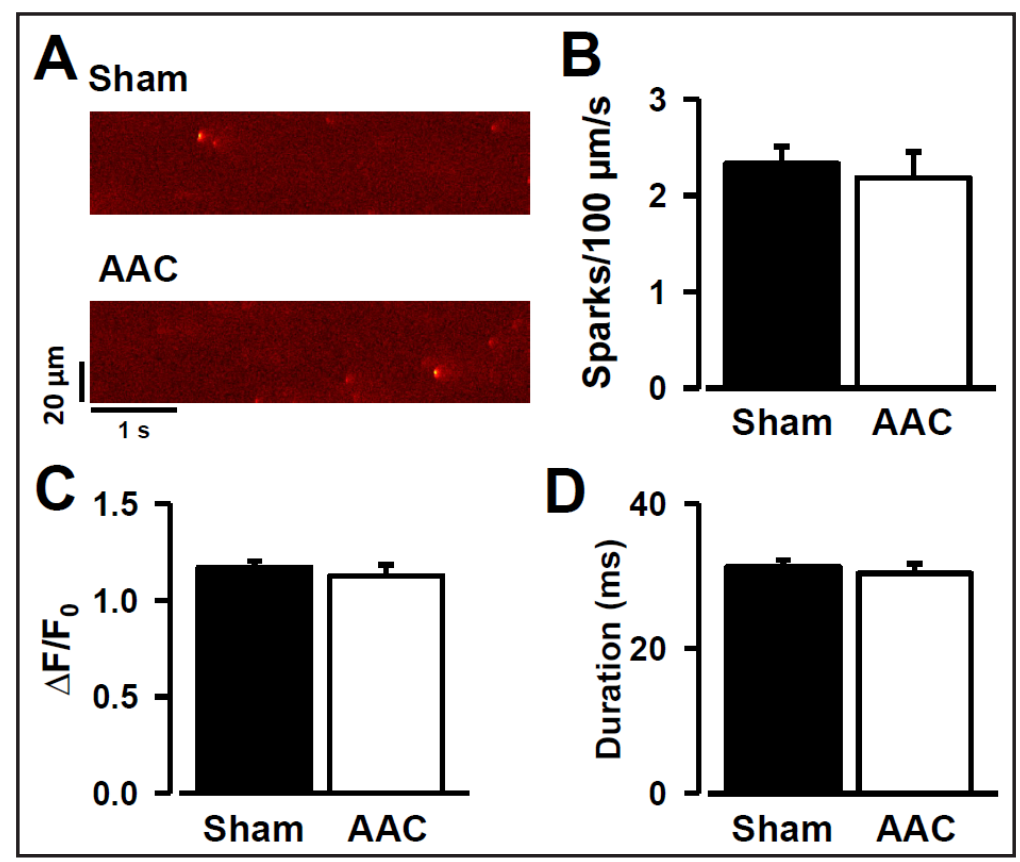

with cytosolic Fluo-4. Despite the decrease in TT and SR density, as well as the apparent diminished SR interconnectivity, all of which potentially could lead to cytosolic $\mathrm{Ca}^{2+}$ handling alterations, we found relatively normal systolic $\mathrm{Ca}^{2+}$ dynamics. Figure 7A shows representative line scan confocal images of $\mathrm{Ca}^{2+}$ transients and spatial average of normalized fluorescence $\left(\mathrm{F} / \mathrm{F}_{0}\right)$ in Sham and $\mathrm{AAC}$ ventricular myocytes, and Fig. $7 \mathrm{~B}$ shows the derivative of the time course of $\Delta \mathrm{F} / \mathrm{F}_{0}(\mathrm{dF} / \mathrm{dt})$ in those cells, as an index of the $\mathrm{SR} \mathrm{Ca}^{2+}$ release flux, and therefore an indication of SR $\mathrm{Ca}^{2+}$ release synchronization. Pooled data showed that $\mathrm{dF} / \mathrm{dt}$ in AAC cells was not significantly different from Sham $(11.06 \pm 1.58$ and $10.36 \pm 0.95 \% / \mathrm{ms}$, for Sham and AAC, respectively, $\mathrm{P}>0.05$; Fig. $7 \mathrm{C}$ ). The $\mathrm{Ca}^{2+}$ transient peak amplitude was also unchanged ( $9.5 \pm 0.2$ and $9.8 \pm 0.2 \Delta \mathrm{F} / \mathrm{F}_{0}$, for Sham and AAC, respectively, P>0.05; Fig. 7D). Finally, the time to $50 \%$ decay $\left(\mathrm{t}_{50 \%}\right)$ of the $\mathrm{Ca}^{2+}$ transient, which is an index of cytosolic $\mathrm{Ca}^{2+}$ removal, mainly by SERCA, was unchanged in AAC $(333 \pm 11$ and $313 \pm 11 \mathrm{~ms}$, for Sham and AAC, respectively, $P$ > 0.5; Fig. 7E).

Figure 8A shows representative confocal images of $\mathrm{Ca}^{2+}$ sparks in AAC and Sham ventricular myocytes. Pooled data for $\mathrm{Ca}^{2+}$ sparks frequency $(2.3 \pm 0.2$ and $2.2 \pm 0.3$ sparks $/ 100 \mu \mathrm{m} / \mathrm{s}$, in Sham and AAC, respectively, P>0.05; Fig. 8B), spark amplitude (1.17 \pm 0.03 and $1.13 \pm 0.06 \Delta \mathrm{F} / \mathrm{F}_{0}$, in Sham and $\mathrm{AAC}$, respectively, $\mathrm{P}>0.05$; Fig. $8 \mathrm{C}$ ) and spark duration ( $31.3 \pm 1.0$ and $30.4 \pm 1.4 \mathrm{~ms}$, in Sham and AAC, respectively, P>0.05; Fig. 8D) were unchanged. Finally, as expected, according to the lack of alterations in systolic and diastolic $\mathrm{Ca}^{2+}$ handling, the SR $\mathrm{Ca}^{2+}$ content, assessed by rapid caffeine application, was similar in both cell types $\left(8.1 \pm 0.6\right.$ and $7.6 \pm 0.5 \Delta \mathrm{F} / \mathrm{F}_{0}$, in Sham and AAC, respectively. Sham $=15$ cells $/ 3$ rats, $\mathrm{AAC}=13$ cells $/ 3$ rats. $\mathrm{P}>0.05$ ).

\section{Discussion}

Much attention has been paid on determining the structural and functional remodeling of ventricular myocytes during HF, particularly in the TT and SR [4, 5, 7, 9, 11, 16, 22, 45]. Nevertheless, HF is the final stage of many diseases, and therefore, remodeling at the whole heart, cellular and molecular levels is highly conspicuous, and clearly correlates with diminished cellular and whole heart performance. In contrast, data about the structure and function of TT and SR in early stages of cardiac hypertrophy are scarce. A couple of studies showed a decrease in TT and overall disarrangement in compensated [14] and 


\section{Cellular Physiology Cell Physiol Biochem 2015;37:1329-1344

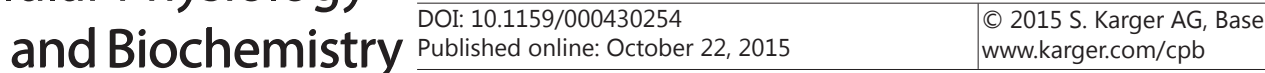 \\ Pérez-Treviño et al.: T-Tubules and Sarcoplasmic Reticulum in Early Hypertrophy}

uncompensated [11] cardiac hypertrophy, suggesting that TT remodeling precedes whole heart dysfunction. However, it is not documented how early TT remodeling appears and whether SR remodeling also occurs in early hypertrophy stages. Here, we provided an assessment of both TT and SR remodeling, complemented with $\mathrm{Ca}^{2+}$ signaling studies, in ventricular myocytes from rats with compensated cardiac hypertrophy after six weeks of AAC. AAC is a well established PO-induced model of cardiac hypertrophy, where the progression of the syndrome can be clearly followed; from compensated to uncompensated stages and overt HF [47]. This is in contrast with other rodent PO-models (e.g. TAC [14]), where uncompensated hypertrophy and HF appear within 8-12 weeks ([14]) or models of cardiac infarct (e.g. coronary artery ligation, [48]), where HF develops within 10 weeks [48], thereby complicating the study of the gradual changes likely to occur in chronic diseases (e.g. hypertension and aortic stenosis). Capasso et al. [47] reported that, in the AAC model, it is necessary to prolong the PO stimuli until 8 months to observe uncompensated cardiac hypertrophy.

At 6 weeks after AAC we confirmed heart hypertrophy (Fig. 1A), similar to what others have reported starting as early as four weeks $[27-29,49,50]$, while cardiac performance, assessed ex vivo, in basal and upon $\beta$-adrenergic stimulation, remained unaltered (Fig. 2). Cellular hypertrophy was conspicuous (Fig. 1C), while TT density modestly decreased without spatial disarrangement (Fig. 3). Moreover, a small decrease in SR density was also found (Fig. 4), and FRAP data showed slower SR fluorophore diffusion (Figs. 5 and 6), although the maximum fluorescence recovery was unchanged (Fig. 6C), suggesting decreased SR interconnectivity or increased path tortuosity. Nevertheless, systolic and diastolic $\mathrm{Ca}^{2+}$ signaling were unchanged (Fig. 7 and 8).

It has been described that in early stages of PO-induced cardiac hypertrophy, the ventricular myocyte volume enlargement is accompanied by a larger increase in contractile myofilaments, TT and SR membranes [51]. The larger increase in TT membrane compensates for the smaller increase in surface sarcolemma, keeping the total sarcolemma to volume ratio constant, which is essential for cell electrophysiology [51]. A larger cell also requires increased SR to match TT and contractile myofilaments, keeping the SR membrane to volume ratio constant, and maintaining ECC performance during this adaptive state [51, 52]. Nevertheless, if the insult persists, these adaptive changes become overwhelmed and the ventricular myocyte enters into the state of maladaptive hypertrophy [53] leading to HF; characterized by altered TT $[4,5,7,9,11,14,22]$ and SR $[9,16]$, which contribute to cell dysfunction $[1,53]$. In this study at 6 weeks following AAC we found a $\sim 78 \%$ myocyte volume increase, while TT and SR densities modestly decreased. These suggest that the expected increases in TT and SR were unable to match cell volume enlargement [51], or that those structures had already started to obliterate. Changes in TT could occur at different levels; a decrease in tubule number, diameter or prolongation within the cell $[12,54]$. TT remodeling also involves rearrangement from the normal organization at the $\mathrm{Z}$ line to the $\mathrm{A}$ band [4, 6, 44], without affecting the overall density [4]. Nevertheless, in our AAC myocytes FFT analysis yielded no change in TT distribution along the longitudinal axis, and the spacing coincided with the normal sarcomere length (Fig. 3C) [4, 6, 14, 44]. Optical limitations of confocal microscopy and data acquisition settings (limited number of slices in the z-axis) precluded analysis of TT diameter or depth projection into the cell. Nevertheless, systolic $\mathrm{Ca}^{2+}$ signaling (Fig. 7) and cardiac performance (Fig. 2) were unaffected, probably because the highly developed TT system in rat myocytes (constituting up to $21-33 \%$ of sarcolemma) [51] can withstand moderate decreases in TT, maintaining relatively normal ECC and heart performance. For TT alterations to have a clear effect in $\mathrm{Ca}^{2+}$ signaling and heart function, TT density has been reported to decrease by $\sim 30-40 \%$ in human HF, pig and rat hypertrophy and HF models [5, 6], and $\sim 24 \%$ in a tachypacing dog model [33]. Others have reported large TT disarrangements (assessed as $\sim 40 \%$ decrease in overall TT integrity) [14] or were accompanied by major disruption in their distribution $[9,13]$ in TAC rodent HF models and in SHRs with HF $[4,11]$. Nevertheless, our data confirm that TT remodeling occurs in compensated cardiac hypertrophy, appearing as early as six weeks after AAC, preceding 


\section{Cellular Physiology Cell Physiol Biochem 2015;37:1329-1344 \begin{tabular}{l|l} 
and Biochemistry Published online: October 22, 2015 & $\begin{array}{l}\text { C 2015 S. Karger AG, Basel } \\
\text { www.karger.com/cpb }\end{array}$ \\
\hline
\end{tabular} \\ Pérez-Treviño et al.: T-Tubules and Sarcoplasmic Reticulum in Early Hypertrophy}

alterations in $\mathrm{Ca}^{2+}$ signaling and contractile dysfunction. Di-8 ANNEPS fluorescence density is a standard technique to assess TT density $[4-6,11,14,33,48]$, and the small difference that we found between both cell types could have not resulted from differential membrane affinity for the fluorophore or from differences in membrane potential, since both cell types were in resting conditions and were quiescent, as evidenced by the lack of motion artifacts, which is essential for acquiring full z-stacks of two-dimensional images. Furthermore, Stilli et al. (2001) [49], using patch clamp reported unaltered resting membrane potential in AAC cells after 4 weeks.

The SR occupies $\sim 4 \%$ of the cell volume $[16,19,51]$, and it is composed of two interconnected domains; jSR, containing most of the RyR, and the free SR (fSR), consisting of narrow tubules connecting to jSR terminals, and containing most of SERCA [19]. We found a discrete $\sim 7 \%$ decrease in SR density, which apparently affected network interconnectivity. In principle, a decrease in SR density could be due to a decrease in the number or size of jSR cisternae $[9,25]$ or in the number or diameter of fSR tubules. A decrease in the number of jSR terminals would affect the magnitude (as suggested by Venetucci et al. (2003) for a global decrease in SR density [55]) and homogeneity of the $\mathrm{Ca}^{2+}$ transient front, since $\mathrm{Ca}^{2+}$ release would not occur at the normal locations. Nevertheless, immunolocalization studies have shown that even after TT misplacement in HF myocytes, "orphan", but functional RyR receptors remain at the $\mathrm{Z}$ line $[4,13]$. Delayed orphan RyR activation is probably triggered by $\mathrm{Ca}^{2+}$ diffusion from nearby active sites $[4,13]$. A decrease in jSR individual size would diminish the number of junctional RyR and the amount of local $\mathrm{Ca}^{2+}$, and both should affect $\mathrm{Ca}^{2+}$ sparks and $\mathrm{Ca}^{2+}$ wave propagation $[9,13,25,56]$. Nevertheless, the $\mathrm{dF} / \mathrm{dt}$ of the $\mathrm{Ca}^{2+}$ transient and the properties of the spontaneous $\mathrm{Ca}^{2+}$ sparks in the AAC cells studied here were unchanged (Figs. 7B-C and 8). These seem reasonable considering the small SR density decrease documented above, which is in contrast with the $\sim 30 \%$ decrease in jSR reported in a catecholaminergic polymorphic ventricular tachycardia model [25] and in the more aggressive TAC model [9], where substantial effects on $\mathrm{Ca}^{2+}$ signaling occurred.

On the other hand, a decrease in the number or diameter of fSR tubules might decrease connectivity with individual jSR and within the whole network, impacting SR $\mathrm{Ca}^{2+}$ diffusion. Normally, the connections between fSR and jSR display some variability, and the extent of connectivity of a given jSR cisternae with a fSR terminal determines the rate of jSR $\mathrm{Ca}^{2+}$ replenishment upon spontaneous $\mathrm{Ca}^{2+}$ release $[17-19,57]$, and therefore should determine RyR refractoriness. Unfortunately, we were unable to study jSR $\mathrm{Ca}^{2+}$ recovery, since MagFluo-4 $\mathrm{K}_{\mathrm{d}}(\sim 70-80 \mu \mathrm{M})$ [58] does not allow to detect the small fluorescence decrease typical of jSR depletion [17, 19], and Fluo $5 \mathrm{~N}\left(\mathrm{~K}_{\mathrm{d}} \sim 400 \mu \mathrm{M}\right.$ [59]) hardly enters into the rat SR [55]. Nevertheless, a decrease in network connectivity should perturb SR $\mathrm{Ca}^{2+}$ diffusion [16], and this might cause heterogeneous SR $\mathrm{Ca}^{2+}$ distribution, which could alter the $\mathrm{Ca}^{2+}$-dependent functional status of RyRs in different jSR terminals [21, 22]. jSR with higher $\mathrm{Ca}^{2+}$ would be more prone to release, creating pro arrhythmic foci $[17,21,22,55]$. Preliminary experiments in AAC cells did not show a difference in the frequency of spontaneous $\mathrm{Ca}^{2+}$ waves, in cells bathed with normal external $\mathrm{Ca}^{2+}$, and the rate of $\mathrm{Ca}^{2+}$ wave propagation slightly increased $(\sim 23 \% ; \mathrm{P}=0.05)$ (Not shown). Earlier observations in cells from a canine model of compensated hypertrophy showed slow $\mathrm{Ca}^{2+}$ waves despite of high $\mathrm{Ca}^{2+}$ spark frequency [22]. In these cells the overall SR $\mathrm{Ca}^{2+}$ content was low, and the high spark frequency was explained arguing that $\mathrm{Ca}^{2+}$ heterogeneity within the SR caused isolated jSR $\mathrm{Ca}^{2+}$-overload, and that slower wave propagation occurred because a given spark could not easily trigger adjacent jSR cisternae with lower $\mathrm{Ca}^{2+}$. Nevertheless, in our AAC cells, whole cell SR $\mathrm{Ca}^{2+}$ and spark properties were unchanged; therefore fewer sites would have abnormally low $\mathrm{Ca}^{2+}$ and should not hamper wave propagation.

While cytosolic $\mathrm{Ca}^{2+}$ signaling was unaffected, we found that the intra SR fluorophore diffusion was markedly slower (Figs. 5 and 6 ) in AAC ventricular myocytes. The $\tau_{\text {recovery }}$ increased by $\sim 44 \%$; while $\tau_{\text {decay }}$ of fluorescence $50 \mu \mathrm{m}$ away (ROI-b) from the bleached area increased by $\sim 82 \%$. Nevertheless, the maximum extent of fluorescence recovery $(\sim 40 \%)$ was unchanged, and occurred with a parallel decrease of $\sim 30 \%$ of the fluorescence at the 


\section{Cellular Physiology Cell Physiol Biochem 2015;37:1329-1344

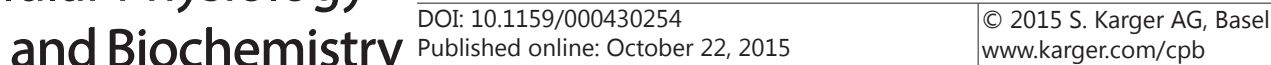 \\ Pérez-Treviño et al.: T-Tubules and Sarcoplasmic Reticulum in Early Hypertrophy}

ROI-b. Since fluorophore diffusion from distant regions within the network still occurred, this suggests that the SR is not fragmented, however, whole cell SR interconnectivity apparently decreased. Nevertheless, the data do not allow determining whether this is due to decreases in the number of fSR connecting units or in the fSR tubules diameter; both of which could delay intra-SR fluorophore diffusion. Furthermore, increased tortuosity of the fSR-jSR connections would also delay diffusion [17, 19, 21]. Nevertheless, intra SR diffusion of $\mathrm{Ca}^{2+}$ should be affected less drastically than in the case of the fluorophore. This is because Mag-Fluo-4 diffusion is slower than that of $\mathrm{Ca}^{2+}$, due to its large molecular size $[17,21]$, and because SR $\mathrm{Ca}^{2+}$ can be restored by SERCA, while FRAP strictly depends on intra SR diffusion of free fluorophore. Nevertheless, since during HF SERCA expression is reduced [60], then the effect of diminished interconnectivity on $\mathrm{Ca}^{2+}$ distribution could become more important than in compensated hypertrophy.

FRAP studies required that $\mathrm{SR} \mathrm{Ca}{ }^{2+}$ remained in steady state throughout the experiment, which was achieved in permeabilized cells. Furthermore, Mag-Fluo-4 should be saturated at steady state $\mathrm{SR} \mathrm{Ca}^{2+}(\sim 1 \mathrm{mM})$ and, for that reason; unintended small $\mathrm{SR} \mathrm{Ca}^{2+}$ changes may not affect fluorescence recordings. Therefore, FRAP should reflect Mag-Fluo-4 diffusion. In pilot experiments (not shown), we found that caffeine application (10 $\mathrm{mM}$ ) decreased MagFluo-4 fluorescence by $\sim 65-70 \%$, and the fluorescence recovery upon caffeine removal was thapsigargin-sensitive (not shown), confirming that a large proportion of the fluorophore was trapped within the SR.

We conclude that in the AAC PO model, which has been used for decades for the study of compensated [28, 29,49,50] and uncompensated [47] cardiac hypertrophy, both TT and SR remodeling start early in the compensated stage of cardiac hypertrophy, without major repercussions in normal $\mathrm{Ca}^{2+}$ cycling and cardiac performance. However, further structural and functional remodeling in those structures, changes in the expression of genes codifying for contractile and $\mathrm{Ca}^{2+}$-cycling proteins $[4,5,9-11,14,16,22]$, would accelerate the cardiac deterioration typical of HF.

\section{Acknowledgements}

We thank A. Salazar-Cantú for helping with some experiments. This work was partially supported by the Endowed Chair in Cardiology, Tecnológico de Monterrey 0020CAT131, as well as by grants from SEP-CONACYT: Projects 156717 (J. Altamirano), 133591 (G. Torre-Amione) and 181460 (N. García), and the Tecnológico de Monterrey and CONACyT scholarships to P. Pérez-Treviño.

\section{Disclosure Statement}

None.

\section{References}

1 Kehat I, Molkentin JD: Molecular pathways underlying cardiac remodeling during pathophysiological stimulation. Circulation 2010;122:2727-2735.

2 Frohlich ED, Gonzalez A, Diez J: Hypertensive left ventricular hypertrophy risk: beyond adaptive cardiomyocytic hypertrophy. J Hypertens 2011;29:17-26.

3 McMullen JR, Jennings GL: Differences between pathological and physiological cardiac hypertrophy: novel therapeutic strategies to treat heart failure. Clin Exp Pharmacol Physiol 2007;34:255-262.

4 Song LS, Sobie EA, McCulle S, Lederer WJ, Balke CW, Cheng H: Orphaned ryanodine receptors in the failing heart. Proc Natl Acad Sci U S A 2006;103:4305-4310. 


\section{Cellular Physiology Cell Physiol Biochem 2015;37:1329-1344 \begin{tabular}{l|l|l|}
\cline { 2 - 3 } DOI: 10.1159/000430254 & O 2015 S. Karger AG, Basel \\
\cline { 1 - 3 }
\end{tabular}

5 Heinzel FR, Bito V, Biesmans L, Wu M, Detre E, von WF, Claus P, Dymarkowski S, Maes F, Bogaert J, Rademakers F, D'hooge J, Sipido K: Remodeling of T-tubules and reduced synchrony of Ca2+ release in myocytes from chronically ischemic myocardium. Circ Res 2008;102:338-346.

6 Lyon AR, MacLeod KT, Zhang Y, Garcia E, Kanda GK, Lab MJ, Korchev YE, Harding SE, Gorelik J: Loss of T-tubules and other changes to surface topography in ventricular myocytes from failing human and rat heart. Proc Natl Acad Sci U S A 2009;106:6854-6859.

7 Biesmans L, Macquaide N, Heinzel FR, Bito V, Smith GL, Sipido KR: Subcellular heterogeneity of ryanodine receptor properties in ventricular myocytes with low T-tubule density. PLoS One 2011;6:e25100.

8 Ibrahim M, Navaratnarajah M, Siedlecka U, Rao C, Dias P, Moshkov AV, Gorelik J, Yacoub MH, Terracciano CM: Mechanical unloading reverses transverse tubule remodelling and normalizes local $\mathrm{Ca}(2+)$-induced $\mathrm{Ca}(2+)$ release in a rodent model of heart failure. Eur J Heart Fail 2012;14:571-580.

9 Wu HD, Xu M, Li RC, Guo L, Lai YS, Xu SM, Li SF, Lu QL, Li LL, Zhang HB, Zhang YY, Zhang CM, Wang SQ: Ultrastructural remodelling of $\mathrm{Ca}(2+)$ signalling apparatus in failing heart cells. Cardiovasc Res 2012;95:430-438.

10 Zhang HB, Li RC, Xu M, Xu SM, Lai YS, Wu HD, Xie XJ, Gao W, Ye H, Zhang YY, Meng X, Wang SQ: Ultrastructural uncoupling between T-tubules and sarcoplasmic reticulum in human heart failure. Cardiovasc Res 2013;98:269-276.

11 Shah SJ, Aistrup GL, Gupta DK, O'Toole MJ, Nahhas AF, Schuster D, Chirayil N, Bassi N, Ramakrishna S, Beussink L, Misener S, Kane B, Wang D, Randolph B, Ito A, Wu M, Akintilo L, Mongkolrattanothai T, Reddy M, Kumar M, Arora R, Ng J, Wasserstrom JA: Ultrastructural and cellular basis for the development of abnormal myocardial mechanics during the transition from hypertension to heart failure. Am J Physiol Heart Circ Physiol 2014;306:H88-100.

12 Bers DM: Excitation-Contraction Coupling and Cardiac Contractile Force, ed 2. Dordrecht/Boston/London, Kluwer Academic Publishers, 2001.

13 Louch WE, Hake J, Mork HK, Hougen K, Skrbic B, Ursu D, Tonnessen T, Sjaastad I, Sejersted OM: Slow Ca(2) $(+)$ sparks de-synchronize $\mathrm{Ca}(2)(+)$ release in failing cardiomyocytes: evidence for altered configuration of $\mathrm{Ca}(2)(+)$ release units? J Mol Cell Cardiol 2013;58:41-52.

14 Wei S, Guo A, Chen B, Kutschke W, Xie YP, Zimmerman K, Weiss RM, Anderson ME, Cheng H, Song LS: T-tubule remodeling during transition from hypertrophy to heart failure. Circ Res 2010;107:520-531.

15 Wu X, Bers DM: Sarcoplasmic reticulum and nuclear envelope are one highly interconnected Ca2+ store throughout cardiac myocyte. Circ Res 2006;99:283-291.

16 Pinali C, Bennett H, Davenport JB, Trafford AW, Kitmitto A: Three-dimensional reconstruction of cardiac sarcoplasmic reticulum reveals a continuous network linking transverse-tubules: this organization is perturbed in heart failure. Circ Res 2013;113:1219-1230.

17 Picht E, Zima AV, Shannon TR, Duncan AM, Blatter LA, Bers DM: Dynamic calcium movement inside cardiac sarcoplasmic reticulum during release. Circ Res 2011;108:847-856.

18 Zima AV, Picht E, Bers DM, Blatter LA: Termination of cardiac Ca2+ sparks: role of intra-SR [Ca2+], release flux, and intra-SR Ca2+ diffusion. Circ Res 2008;103:e105-e115.

19 Brochet DX, Yang D, Di MA, Lederer WJ, Franzini-Armstrong C, Cheng H: Ca2+ blinks: rapid nanoscopic store calcium signaling. Proc Natl Acad Sci U S A 2005;102:3099-3104.

20 Gyorke S, Gyorke I, Lukyanenko V, Terentyev D, Viatchenko-Karpinski S, Wiesner TF: Regulation of sarcoplasmic reticulum calcium release by luminal calcium in cardiac muscle. Front Biosci 2002; 7:d1454-d1463.

21 Bers DM, Shannon TR: Calcium movements inside the sarcoplasmic reticulum of cardiac myocytes. J Mol Cell Cardiol 2013;58:59-66.

22 Song LS, Pi Y, Kim SJ, Yatani A, Guatimosim S, Kudej RK, Zhang Q, Cheng H, Hittinger L, Ghaleh B, Vatner DE, Lederer WJ, Vatner SF: Paradoxical cellular Ca2+ signaling in severe but compensated canine left ventricular hypertrophy. Circ Res 2005;97:457-464.

23 Vega AL, Yuan C, Votaw VS, Santana LF: Dynamic changes in sarcoplasmic reticulum structure in ventricular myocytes. J Biomed Biotechnol 2011;2011:382586.

24 Knollmann BC, Chopra N, Hlaing T, Akin B, Yang T, Ettensohn K, Knollmann BE, Horton KD, Weissman NJ, Holinstat I, Zhang W, Roden DM, Jones LR, Franzini-Armstrong C, Pfeifer K: Casq2 deletion causes sarcoplasmic reticulum volume increase, premature $\mathrm{Ca} 2+$ release, and catecholaminergic polymorphic ventricular tachycardia. J Clin Invest 2006;116:2510-2520. 


\section{Cellular Physiology Cell Physiol Biochem 2015;37:1329-1344

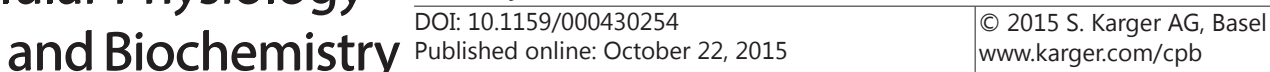 \\ Pérez-Treviño et al.: T-Tubules and Sarcoplasmic Reticulum in Early Hypertrophy}

25 Liu N, Denegri M, Dun W, Boncompagni S, Lodola F, Protasi F, Napolitano C, Boyden PA, Priori SG: Abnormal propagation of calcium waves and ultrastructural remodeling in recessive catecholaminergic polymorphic ventricular tachycardia. Circ Res 2013;113:142-152.

26 Swift F, Franzini-Armstrong C, Oyehaug L, Enger UH, Andersson KB, Christensen G, Sejersted OM, Louch WE: Extreme sarcoplasmic reticulum volume loss and compensatory T-tubule remodeling after Serca2 knockout. Proc Natl Acad Sci U S A 2012;109:3997-4001.

27 Stanek KA, Coleman TG, Murphy WR: Overall hemodynamic pattern in coarctation of the abdominal aorta in conscious rats. Hypertension 1987;9:611-618.

28 Matsui H, Yokoyama T, Tanaka C, Sunaga H, Koitabashi N, Takizawa T, Arai M, Kurabayashi M: Pressure mediated hypertrophy and mechanical stretch up-regulate expression of the long form of leptin receptor (ob-Rb) in rat cardiac myocytes. BMC Cell Biol 2012;13:37.

29 Stilli D, Bocchi L, Berni R, Zaniboni M, Cacciani F, Chaponnier C, Musso E, Gabbiani G, Clement S: Correlation of alpha-skeletal actin expression, ventricular fibrosis and heart function with the degree of pressure overload cardiac hypertrophy in rats. Exp Physiol 2006;91:571-580.

30 Arreguin F, Garcia N, Hernandez-Resendiz S, Buelna-Chontal M, Correa F, Olin-Sandoval V, Medina-Campos ON, Pedraza-Chaverri J, Zazueta C: Attenuation of oxidant damage in the postconditioned heart involves non-enzymatic response and partial catalytic protection. Exp Physiol 2012;97:1119-1130.

31 Hryshko LV, Stiffel V, Bers DM: Rapid cooling contractures as an index of sarcoplasmic reticulum calcium content in rabbit ventricular myocytes. Am J Physiol 1989;257:H1369-H1377.

32 Satoh H, Delbridge LM, Blatter LA, Bers DM: Surface:volume relationship in cardiac myocytes studied with confocal microscopy and membrane capacitance measurements: species-dependence and developmental effects. Biophys J 1996;70:1494-1504.

33 He J, Conklin MW, Foell JD, Wolff MR, Haworth RA, Coronado R, Kamp TJ: Reduction in density of transverse tubules and L-type $\mathrm{Ca}(2+)$ channels in canine tachycardia-induced heart failure. Cardiovasc Res 2001;49:298-307.

34 Heinzel FR, Bito V, Volders PG, Antoons G, Mubagwa K, Sipido KR: Spatial and temporal inhomogeneities during Ca2+ release from the sarcoplasmic reticulum in pig ventricular myocytes. Circ Res 2002;91:10231030.

35 Hunton DL, Zou L, Pang Y, Marchase RB: Adult rat cardiomyocytes exhibit capacitative calcium entry. Am J Physiol Heart Circ Physiol 2004;286:H1124-H1132.

36 Kuum M, Kaasik A, Joubert F, Ventura-Clapier R, Veksler V: Energetic state is a strong regulator of sarcoplasmic reticulum $\mathrm{Ca} 2+$ loss in cardiac muscle: different efficiencies of different energy sources. Cardiovasc Res 2009;83:89-96.

37 Kojima A, Kitagawa H, Omatsu-Kanbe M, Matsuura H, Nosaka S: Sevoflurane protects ventricular myocytes from $\mathrm{Ca} 2+$ paradox-mediated Ca2+ overload by blocking the activation of transient receptor potential canonical channels. Anesthesiology 2011;115:509-522.

38 Harmer AR, Gallacher DV, Smith PM: Correlations between the functional integrity of the endoplasmic reticulum and polarized $\mathrm{Ca} 2+$ signalling in mouse lacrimal acinar cells: a role for inositol 1,3,4,5-tetrakisphosphate. Biochem J 2002;367:137-143.

39 Lukyanenko V, Gyorke S: Ca2+ sparks and Ca2+ waves in saponin-permeabilized rat ventricular myocytes. J Physiol 1999;521:575-585.

40 Bers DM, Patton CW, Nuccitelli R: A practical guide to the preparation of Ca2+ buffers. Methods Cell Biol 1994;40:3-29.

41 Bassani JW, Bassani RA, Bers DM: Relaxation in rabbit and rat cardiac cells: species-dependent differences in cellular mechanisms. J Physiol 1994;476:279-293.

42 Cheng H, Song LS, Shirokova N, Gonzalez A, Lakatta EG, Rios E, Stern MD: Amplitude distribution of calcium sparks in confocal images: theory and studies with an automatic detection method. Biophys J 1999;76:606617.

43 Picht E, Zima AV, Blatter LA, Bers DM: SparkMaster: automated calcium spark analysis with ImageJ. Am J Physiol Cell Physiol 2007;293:C1073-C1081.

44 Kawai M, Hussain M, Orchard CH: Excitation-contraction coupling in rat ventricular myocytes after formamide-induced detubulation. Am J Physiol 1999;277:H603-H609. 


\section{Cellular Physiology Cell Physiol Biochem 2015;37:1329-1344 \begin{tabular}{l|l|l|} 
DOI: 10.1159/000430254 & O 2015 S. Karger AG, Basel \\
and Biochemistry & Published online: October 22, 2015 & pargercom/cpb
\end{tabular} \\ Pérez-Treviño et al.: T-Tubules and Sarcoplasmic Reticulum in Early Hypertrophy}

45 Lu FH, Fu SB, Leng X, Zhang X, Dong S, Zhao YJ, Ren H, Li H, Zhong X, Xu CQ, Zhang WH: Role of the calciumsensing receptor in cardiomyocyte apoptosis via the sarcoplasmic reticulum and mitochondrial death pathway in cardiac hypertrophy and heart failure. Cell Physiol Biochem 2013;31:728-743.

46 Lin Y, Zhang X, Wang L, Zhao Y, Li H, Xiao W, Xu C, Liu J: Polyamine depletion attenuates isoproterenolinduced hypertrophy and endoplasmic reticulum stress in cardiomyocytes. Cell Physiol Biochem 2014;34:1455-1465.

47 Capasso JM, Palackal T, Olivetti G, Anversa P: Left ventricular failure induced by long-term hypertension in rats. Circ Res 1990;66:1400-1412.

48 Louch WE, Bito V, Heinzel FR, Macianskiene R, Vanhaecke J, Flameng W, Mubagwa K, Sipido KR: Reduced synchrony of $\mathrm{Ca} 2+$ release with loss of T-tubules-a comparison to $\mathrm{Ca} 2+$ release in human failing cardiomyocytes. Cardiovasc Res 2004;62:63-73.

49 Stilli D, Sgoifo A, Macchi E, Zaniboni M, De IS, Cerbai E, Mugelli A, Lagrasta C, Olivetti G, Musso E: Myocardial remodeling and arrhythmogenesis in moderate cardiac hypertrophy in rats. Am J Physiol Heart Circ Physiol 2001;280:H142-H150.

50 Berni R, Savi M, Bocchi L, Delucchi F, Musso E, Chaponnier C, Gabbiani G, Clement S, Stilli D: Modulation of actin isoform expression before the transition from experimental compensated pressure-overload cardiac hypertrophy to decompensation. Am J Physiol Heart Circ Physiol 2009;296:H1625-H1632.

51 Page E, McCallister LP: Quantitative electron microscopic description of heart muscle cells. Application to normal, hypertrophied and thyroxin-stimulated hearts. Am J Cardiol 1973;31:172-181.

52 Anversa P, Olivetti G, Melissari M, Loud AV: Stereological measurement of cellular and subcellular hypertrophy and hyperplasia in the papillary muscle of adult rat. J Mol Cell Cardiol 1980;12:781-795.

53 Dorn GW, Robbins J, Sugden PH: Phenotyping hypertrophy: eschew obfuscation. Circ Res 2003;92:11711175.

54 Brette F, Orchard C: T-tubule function in mammalian cardiac myocytes. Circ Res 2003;92:1182-1192.

55 Venetucci L, Trafford AW, Eisner DA: Illuminating sarcoplasmic reticulum calcium. Circ Res 2003;93:4-5.

56 Lee YS, Liu OZ, Hwang HS, Knollmann BC, Sobie EA: Parameter sensitivity analysis of stochastic models provides insights into cardiac calcium sparks. Biophys J 2013;104:1142-1150.

57 Zima AV, Picht E, Bers DM, Blatter LA: Partial inhibition of sarcoplasmic reticulum ca release evokes longlasting ca release events in ventricular myocytes: role of luminal ca in termination of ca release. Biophys J 2008;94:1867-1879.

58 Hollingworth S, Gee KR, Baylor SM: Low-affinity Ca2+ indicators compared in measurements of skeletal muscle Ca2+ transients. Biophys J 2009;97:1864-1872.

59 Shannon TR, Guo T, Bers DM: Ca2+ scraps: local depletions of free [Ca2+] in cardiac sarcoplasmic reticulum during contractions leave substantial Ca2+ reserve. Circ Res 2003;93:40-45.

60 Periasamy M, Bhupathy P, Babu GJ: Regulation of sarcoplasmic reticulum Ca2+ ATPase pump expression and its relevance to cardiac muscle physiology and pathology. Cardiovasc Res 2008;77:265-273. 